\title{
África e africanos na diáspora africana: os usos de bancos de dados relacionais ${ }^{*}$
}

\author{
Gwendolyn Midlo Hall
}

\begin{abstract}
Os estudos afro-americanos, melhor descritos como estudos negro-americanos, são em sua maior parte superficiais e incompletos, referindo-se aos negros sem conhecê-los. O pesquisador típico não consegue libertar-se dessa tendência à fragmentação e à superficialidade, pois não considera os africanos como individuos provenientes de uma sociedade com regras e valores próprios... como pessoas arrancadas de uma cultura particular que não pode ser apagada pelo simples ato de atravessar o Atlântico. De seres humanos repletos de cultura e conhecimento, os negros foram transformados em mera mercadoria: toneladas de ébano. Nicolás Ngou-Mve, Historia de la población negra en México.
\end{abstract}

Em artigo publicado na American Historical Review de 2007, "Agency and Diaspora in Atlantic History”, David Eltis, Philip Morgan e David Richardson fazem duas importantes afirmações: 1) que o artigo apresenta um modelo novo e superior para a interpretação da formação da cultura "crioula" nas Américas, e 2) que ele desafia a crença de que os africanos tiveram um papel relevante na introdução e tecnologia do cultivo e processamento de arroz nas Américas. Para tais conclusões acerca do cultivo de arroz, os autores baseiam-se principalmente em cálculos a partir do Trans-Atlantic Slave Trade Database, Versão 2 (referida daqui por diante como TSTD2), usando-o como ferramenta para estudar como se distribuíram os africanos escravizados, provenientes de regiōes na África onde se cultivava o arroz, nas regiôes da América que exportavam arroz para a Europa. ${ }^{1}$

Os autores alegam ter feito uma descoberta importante e inovadora acerca da formação da cultura "crioula" nas Américas. A partir daí, eles reavivam e retomam uma discussão - não relacionada ao tema central de sua pesquisa - realizada em 1991 e editada por Philip Morgan, na qual, diversos especialistas criticavam o livro de David Hackett Fischer intitulado Albion's Seed: Four British Folkways in America. O livro de Fischer trata dos colonizadores britânicos nos Estados Unidos. Especialistas no tema jamais afirmaram que as culturas britânicas foram apagadas pela travessia transatlântica. A metodologia de Fischer não serviu como modelo para os estudos da diáspora africana. ${ }^{2}$

\footnotetext{
* Tenho uma grande dívida com o National Endowment for the Humanities e com os contribuintes do nosso país [Estados Unidos da América], que financiaram a expansão do meu Louisiana Slave Database, como parte dos contratos de pesquisa colaborativa, números RO-22619-1901 e 1993, "Africans in Spanish and Early American Louisiana", com Patrick Manning como coinvestigador. Também recebi grande apoio financeiro da Fundação Guggenheim, assim como contribuições generosas do Ministério da Cultura da França, do Programa para Cooperação Cultural entre o Ministério da Cultura da Espanha e as universidades dos Estados Unidos, e do Louisiana Endowment for the Humanities. Steven Mintz generosamente tem concorrido com seu entusiasmo, tempo e apoio por, até agora, quase uma década, inclusive para este artigo. Paul E. Lovejoy, diretor do Harriet Tubman Institute for Research on the Global Migrations of African Peoples, da Universidade de York, em Toronto, Canadá, seus estudantes de graduação e nossos colegas nessa área de conhecimento, desempenharam uma papel muito especial. Sou grata a Maureen Hewitt, editora-chefe da LSU Press, por seu trabalho inovador e entusiasmado, no preparo da versão em CD-ROM do banco de dados para publicação (Databases for the Study of Afro-Louisiana History and Genealogy, 1699-1860: Computerized Information from Original Manuscript Sources, 2000). Outros colegas deram seu tempo e atenção para me ajudar e me encorajar depois do [furacão] Katrina e para tornar esse artigo muito melhor do que era: O. Vernon Burton, Rina Cáceres, Yvonne Captain-Hidalgo, Judith A. Carney, Douglas B. Chambers, Matt D. Childs, Howard Dodson, Joseph C. Dorsey, Christopher Dunn, David Hackett Fischer, Michael A. Gomez, Rebecca L. Hall, Joseph E. Harris, Susan Heywood, Joseph E. Inikori, Aondofe Joseph-Ernest Iyo, Eileen M. Julien, Jane I. Landers, Juan Manuel de la Serna, Joseph C. Miller, Nell Irvin Painter, Ibrahima Seck, Ned Sublette, Ibrahim K. Sundiata e John K. Thornton.
} 


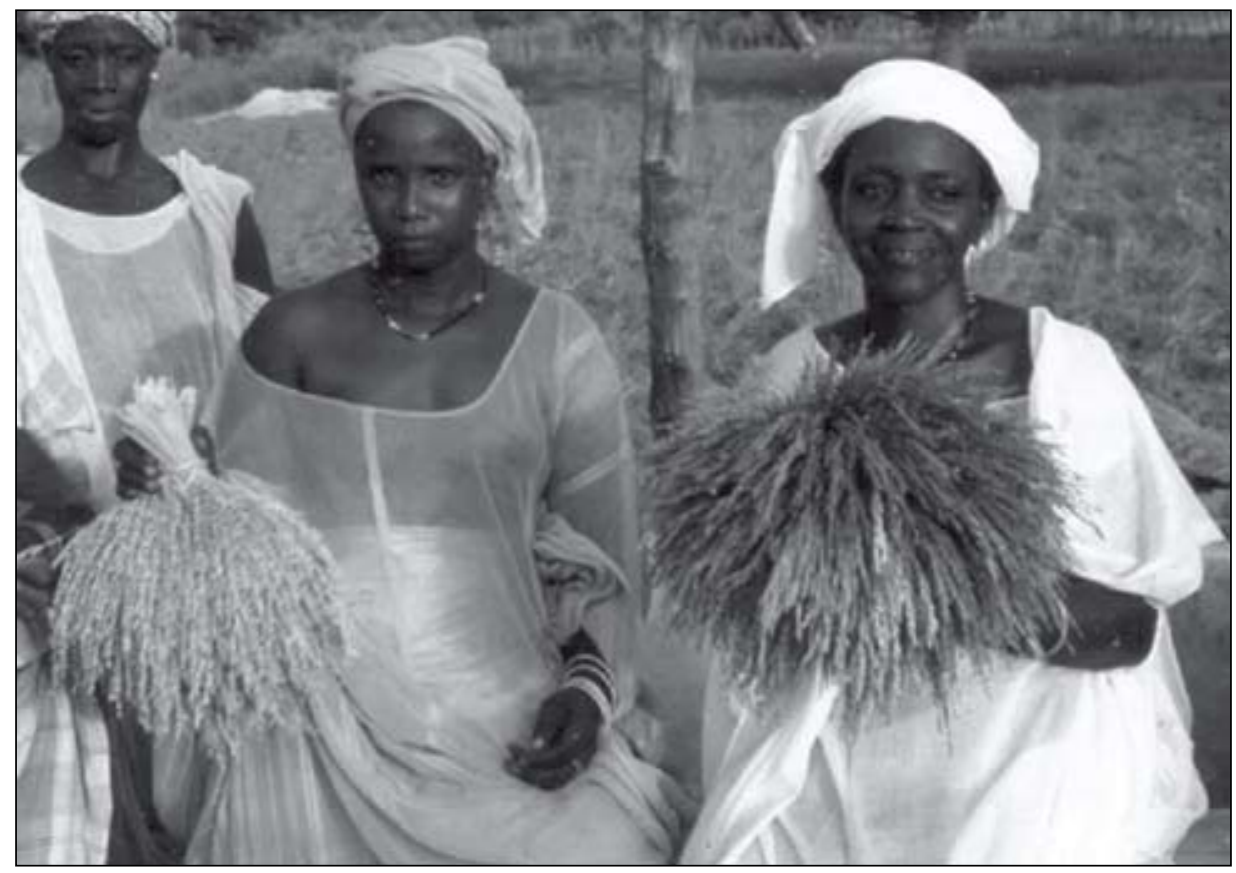

Figura 1: Mulheres mandinga exibindo feixes de arroz africano e asiático. Fotografia de Judith A. Carney.

$\mathrm{O}$ artigo distorce o trabalho dos diversos pesquisadores que critica. Nossas variadas metodologias são reduzidas a uma defesa monolítica de culturas estáticas - como "sementes" trazidas do Velho Mundo - que permaneceram nas Américas como "enclaves culturais". "Ao invés de definir a questão como sendo, apenas, de transferências e de condutas", escrevem os autores, "devemos pensar, também, em transformações e em circuitos sobrepostos. Ao invés de postular que escravos e proprietários de plantations sempre agiram conscientemente, devemos considerar a possibilidade de que eles, muitas vezes, reagiam a forças mercadológicas invisíveis. Ao invés de assumir que os imigrantes permaneceram vinculados conservadoramente a formas tradicionais, podemos vê-los, também, como experimentadores e improvisadores". ${ }^{3}$

Os especialistas criticados em "Agency and Diaspora..." compartilham apenas uma interpretação: a de que o conhecimento e a cultura dos africanos originários de determinadas regiōes costeiras e pertencentes a determinadas etnias não foram extintos pela travessia atlântica. Esta historiadora, por exemplo, escreveu que o processo de "crioulização" nas Américas respondeu a fatores variados e sujeitos a mudanças, incluindo os padrôes estabelecidos pela chegada de africanos oriundos de regiōes e etnias particulares; as proporçôes de homens e mulheres e os padrões de casamento e parentesco; a velocidade com que os imigrantes começaram a procriar e a extensão da fusão biológica entre diferentes povos; a força demográfica e militar da população americana nativa; a possibilidade de a geografia facilitar a manutenção de comunidades de escravos fugidos (maroons); as prioridades econômicas, estratégicas e militares dos poderes colonizadores; a extensão da emancipação de escravos alforriados, sua força demográfica e status social; os usos militares e policiais de escravos e negros livres; a demanda de trabalho para a produção dos principais artigos para exportação, à medida que a economia se desenvolvia; e as políticas de controle social que se refletiam nas várias tradições e instituições políticas e religiosas europeias e como elas eram efetivamente impostas. Conceitos e definições acerca da "crioulização" nas Américas variam entre os especialistas cujos trabalhos são criticados em "Agency and Diaspora...”. A versão mais recente é a conclusão de Linda Heywood e John Thornton de que a geração de africanos que atravessou o Atlântico e que moldou as culturas "crioulas" na América britânica e na América holandesa, antes de 1660, era formada sobretudo por africanos católicos e europeizados da região centro-ocidental da África. ${ }^{4}$ 
O resto do artigo minimiza a importância da transferência da tecnologia africana para as Américas na questão do cultivo e processamento do arroz. Embora algumas fontes qualitativas incidentais tenham sido usadas, o argumento baseia-se predominantemente em cálculos feitos a partir do TSTD2. David Eltis, Stephen Behrendt, David Richardson e Manolo Florentino merecem grande mérito por seu incansável trabalho nesse banco de dados, incluindo os avanços tecnológicos extraordinários em relação à primeira versão, o TSTD1. Foram adicionados milhares de registros sobre navegações brasileiras e portuguesas, corrigindo a distorção do TSTD1, que mantinha seu foco na Inglaterra. $\mathrm{O}$ banco de dados tornou-se mais fácil de utilizar e é acessível gratuitamente ao público, como um sistema de código livre. Ele permite aos usuários fazer cálculos, correções e acréscimos e pode responder a muitas questões importantes sobre o tráfico transatlântico de escravos. Entretanto, quando se trata de certo tipo de questão, suas limitações devem ser levadas em conta. Ele não consegue responder às perguntas sobre o cultivo de arroz propostas em "Agency and Diaspora...".

Os bancos de dados históricos são ferramentas magníficas e inovadoras. Eles podem integrar uma imensa quantidade de dados objetivos e detalhados em padrões amplos, permitindo análises relacionadas a um determinado intervalo de tempo e a um específico lugar. A vasta quantidade de informações que podem conter e analisar é uma grande vantagem, especialmente no caso de estudos amplos e comparativos. Os bancos de dados podem responder a perguntas que seriam insolúveis com metodologias mais tradicionais; podem responder a outras, parcial ou provisoriamente; e podem ainda ajudar a responder a outro tipo de pergunta, combinando cálculos quantitativos com os resultados de pesquisas realizadas em outras disciplinas, como a arqueologia, a antropologia, a linguística e a geografia, assim como a história tradicional. Porém, há algumas questões que simplesmente estão além das suas potencialidades. Tudo depende das perguntas para as quais um determinado banco de dados foi projetado para responder. Os bancos de dados podem ser mais rígidos que fontes qualitativas; ao usá-los, os especialistas devem ter em mente que, só porque algo não está incluído em um documento histórico ou em um banco de dados, não significa que não tenha acontecido. Há informações importantes que nunca foram documentadas; há documentos que ainda não foram encontrados e estudados. O TSTD1 e o TSTD2 foram projetados para conter, unicamente, informaçôes sobre viagens documentadas e estudadas, realizadas por navios que cruzaram o Atlântico transportando escravos. "Agency and Diaspora..." mal considera o processo de redistribuição que aconteceu quando esses novos africanos foram primeiramente vendidos nas Américas, então reembarcados em outros navios e subsequentemente deslocados por água e/ou por terra para outros lugares, antes de atingirem seus diversos destinos finais. Nesse processo, eles, às vezes, eram agrupados por região de origem e/ou por classificação étnica, para que os compradores pudessem adquirir, sem dificuldades, os novos africanos que preferissem. ${ }^{6}$

Há problemas relativos tanto à rigidez, quanto à omissão de dados importantes no TSTD2. Ele foi criado a partir de pesquisas em documentos manuscritos originais realizadas por muitos historiadores durante os últimos 40 anos ou mais. Cada registro cobre uma específica viagem transatlântica de tráfico de escravos. Os campos em um banco de dados contêm informaçôes sobre cada registro incluído. Eles são projetados para responder às perguntas que os criadores do banco de dados querem fazer e não, necessariamente, para fornecer informaçóes contidas nos documentos originais. A menos que um banco de dados tenha sido planejado para ser flexível, uma vez que os campos tenham sido definidos e uma quantidade substancial de dados tenha sido inserida, adicionar novos campos pode ser trabalhoso, demorado e dispendioso. O TSTD2 continua preso às mesmas questôes que os especialistas passaram a examinar, desde a publicação, em 1969, de The Atlantic Slave Trade: A Census, de Phillip D. Curtin, mas com uma limitação importante: não existe um campo para a inserção de dados sobre as etnias africanas. Exceto por algumas informações inteiramente quantitativas, tais como sexo, faixa etária e óbitos - quando esta informação foi registrada nos documentos e, depois, anotada e publicada pelos historiadores que os estudaram -, o TSTD2 não focaliza informações sobre os escravos africanos nos navios. Os campos não foram modificados entre o TSTD1 e o TSTD2. 
Evidentemente, os historiadores registram somente o que consideram relevante, portanto, não podemos ter conhecimento daquilo que os primeiros pesquisadores optaram por não registrar. Em alguns casos, informações que, de fato, foram registradas pelo especialista que conduziu a pesquisa inicial não foram inseridas no banco de dados porque não havia campo destinado a elas. É possível que entre essas omissões estejam as informações sobre etnias africanas que Eltis, Morgan e Richardson descartaram por considerarem imprecisas e, talvez por isso, sem importância. ${ }^{7}$ As informações sobre etnias africanas no tráfico transatlântico de escravos foram documentadas? Sim. Com que amplitude? Sem consultar os documentos originais, não podemos saber. Se não havia campos no TSTD2 nos quais pudessem ser registradas tais informações, assim como determinados conteúdos dos documentos originais, esses dados não estão disponíveis para nós. Assim, a vantagem crucial de usar documentos manuscritos originais fica perdida. Talvez haja muito pouca informação nos documentos relativos ao tráfico escravo transatlântico sobre africanos a bordo dos navios; ou talvez, como observou Nicolás Ngou-Mve, aqueles que conduziram a pesquisa utilizando os documentos originais não consideraram essa informação importante o suficiente para ser registrada. Dessa maneira, quando os editores do TSTD2 não fizeram, eles mesmos, a pesquisa inicial, as informações que constavam das fontes originais foram, pela segunda vez, removidas. Ngou-Mve apela aos historiadores que examinem todos os documentos novamente, mesmo que já tenham sido estudados por outros pesquisadores. A experiência desta autora com documentos sobre o tráfico transatlântico de escravos limita-se à Luisiana, mas sustenta a conclusão de Ngou-Mve. ${ }^{8}$

Os bancos de dados históricos e as novas mídias precisam ir além de questôes puramente quantificáveis. Como sugere Daniel J. Cohen,

É extremamente importante concentrar o potencial total da mídia e certificar-se de que a história digital não é simplesmente um eco de algoritmos ou processos quantitativos para registros digitais em grande quantidade, a serviço da análise e descoberta de fontes (...) igualmente importantes são as redes de trabalho e as possibilidades colaborativas da mídia - isto é, focalizar os seres humanos ao invés das máquinas. ${ }^{9}$

A possibilidade de busca e visualização proporcionada pela tecnologia avançada facilita esse progresso. A visualização vai nos permitir consultar os documentos originais, cujos conteúdos foram filtrados por bancos de dados rígidos e puramente quantificáveis.

Durante as duas últimas décadas, houve uma mudança sísmica na percepção de documentos relativos aos africanos e seus descendentes nas Américas. A crença de que fontes manuscritas originais não existiam ou eram extremamente raras deu lugar ao reconhecimento de que, nas Américas, há uma extraordinária quantidade de documentos em arquivos históricos, tribunais de justiça, portos, museus e coleções privadas, por toda a parte. O banco de dados desta autora sobre os escravos da Luisiana foi iniciado em 1984. Tendo como foco os indivíduos escravizados, ele foi criado quase que totalmente a partir de documentos manuscritos originais. Contém quase todas as informações disponíveis nos documentos originais, sobre cada descrição de escravo, incluindo dados não passíveis de quantificação. ${ }^{10}$

As limitações do TSTD2 põem em dúvida a crítica de Eltis, Morgan e Richardson ao conhecido trabalho de Judith A. Carney sobre a transferência do cultivo do arroz da África para as Américas. Ela realizou uma série, realmente impressionante, de pesquisas variadas e exaustivas e as usou criteriosamente. Carney é uma geógrafa poliglota e multidisciplinar que se inspirou, em seus estudos de documentos históricos originais, no trabalho pioneiro dos historiadores Daniel C. Littlefield e Peter H. Wood. Seu conhecimento sobre geografia e tecnologias agrícolas amplia sua percepção acerca dos significados dessas fontes primárias. A partir das mais antigas fontes manuscritas e de publicaçôes de observadores portugueses, produzidas em meados do século XV, Carney documenta, de forma cabal, o complexo, bem estabelecido e difundido cultivo de arroz em diversos ambientes ao longo das costas da Alta Guiné e ao longo de seus rios. Ela emprega várias abordagens, inclusive fontes documentais de ambos os lados do 
Atlântico, ao longo dos cinco séculos de tráfico de escravos no Atlântico, bem como um profundo trabalho de campo na África e nas Américas. Em contrapartida, Eltis, Morgan e Richardson fundamentam suas conclusões em frágeis evidências encontradas em documentos relativos a vinte viagens da Royal African Company a Gâmbia e Serra Leoa, entre 1779 e 1788. Tal amostra é muito pequena e limitada no tempo. Não havia campo para o registro de tais informaçôes no TSTD2; desse modo, eles tiveram que consultar documentos originais. Não obstante, eles afirmam: "A partir dessa evidência, mulheres [africanas] não moíam arroz nas travessias atlânticas". ${ }^{11}$

É possível que mulheres moessem arroz nos navios do tráfico escravo, mas que essas atividades não estivessem registradas em documentos, ou que tais documentos tenham sobrevivido, mas que ainda não tenham sido encontrados; ou que os primeiros pesquisadores não tivessem registrado essa informação; ou ainda, que eles registraram, mas, que as informações não tivessem sido incluídas no TSTD2. Carney tem provas de mulheres batendo grãos de arroz em um navio do tráfico escravo, em 1796, assinalando que se trata de apenas um único caso claramente documentado. Ela especula como as sementes de arroz puderam ser introduzidas nas Américas, sem chegar, contudo, a conclusões sólidas. Ela discute a evidência de que a introdução do arroz ocorreu a partir de direções variadas e múltiplas, no percurso entre a África e as Américas, ao longo dos séculos. Neste sentido, Carney não poderia ter afirmado, como disseram Eltis, Morgan e Richardson, que "uma única escrava africana carregando alguns grãos de arroz nos cabelos pode tornar-se tudo o que é necessário para sustentar a tese". ${ }^{12}$ Uma das principais questões que ela aponta em seu livro, Black Rice: The African Origins of Rice Cultivation in the Américas, é que as trocas entre Europa, África e o Novo Mundo [Columbian Exchange] envolviam a transferência não só de grãos, mas também de sistemas de cultivo, incluindo técnicas de processamento transplantadas dos locais de domesticação para outras regiōes do mundo Atlântico. ${ }^{13}$ É por isso que ela emprega a palavra "sistemas". Eltis, Morgan e Richardson retiram a palavra "sistemas" do contexto, ${ }^{14}$ depreciando todo o trabalho de Carney, a partir de críticas insustentáveis.

Está correta a afirmação, em "Agency and Diaspora...", de que "parte da estratégia para manter vivas propriedades valiosas na travessia transatlântica era assegurar que os escravos recebessem o alimento a que estavam acostumados". ${ }^{15}$ Os autores dizem que mais painço do que arroz foi embarcado nas doze viagens de tráfico escravo que estudaram, e cujo ponto de partida foi a Alta Guiné, entre 1779 e 1788. Mas o arroz, não o painço, era uma importante cultura alimentar nas Américas. Os autores sugerem que os africanos, assim como os europeus, podem ter improvisado seus padrões alimentares nas Américas, minimizando as preferências dos escravos africanos por arroz. ${ }^{16}$ Será que a necessidade de permitir que os escravos africanos seguissem seus padrōes alimentares tradicionais, a fim de mantê-los vivos, desapareceu após a travessia atlântica?

Tabela 1: Proporção de homens e mulheres das etnias da Alta Guiné na Luisiana (faixa etária 15-39), 1719-1820.

\begin{tabular}{|c|c|c|c|}
\hline & Homens & Mulheres & Total \\
\hline Bamana & $\mathrm{n}=20587.2 \%$ & $\mathrm{n}=3012.8 \%$ & 235 \\
\hline Mandinga & $\mathrm{n}=35367.9 \%$ & $\mathrm{n}=16732.1 \%$ & 520 \\
\hline Nar/Berberes & $\mathrm{n}=4970.0 \%$ & $\mathrm{n}=2130.0 \%$ & 70 \\
\hline Fulanis & $\mathrm{n}=8069.6 \%$ & $\mathrm{n}=3530.4 \%$ & 115 \\
\hline Jalofos/Senegal & $\mathrm{n}=22561.5 \%$ & $\mathrm{n}=14138.5 \%$ & 366 \\
\hline TOTAL & $\mathrm{n}=91269.8 \%$ & $\mathrm{n}=39430.2 \%$ & 1,306 \\
\hline
\end{tabular}

Calculado a partir de HALL, Gwendolyn Midlo. Louisiana Slave Database, 1719-1820 
Eltis, Morgan e Richardson criticam Carney por exagerar o papel das mulheres na produção de arroz nas Américas. Apontam para a proporção masculina relativamente alta nos navios oriundos da Alta Guiné. Mas, esses cálculos não nos dizem nada sobre as proporções de homens e mulheres entre os escravos de etnias produtoras de arroz, ou sobre as preferências dos empregadores por mulheres dessas etnias. Escrevem os autores que "o número e a percentagem de africanos com experiência de cultivo de arroz deve ter sido bem abaixo do número de escravos que deixaram a Alta Guiné". ${ }^{17}$ Isso sem dúvida é verdadeiro; todavia, por isso mesmo, seus estudos sobre a proporção de homens e mulheres escravos oriundos de toda a costa da Alta Guiné não são elucidativos no que diz respeito aos produtores de arroz. $\mathrm{Na}$ maior parte do século XVIII e início do XIX, guerreiros escravos foram despachados, em grande número, pelos rios Senegal e Gâmbia, principalmente os Bamana (Bambara), durante a década de 1720 , antes que a designação "Bambara" assumisse um significado mais amplo, vago e genérico. Muitos guerreiros capturados foram embarcados para as Américas a partir de Serra Leoa e Senegâmbia, aumentando a proporção de escravos do sexo masculino. A proporção masculina era maior entre as etnias capturadas, mais frequentemente, em combates ou entre as populações de criadores de gado. A proporção de homens e mulheres entre os africanos da Alta Guiné variava de acordo com a etnia. Alguns guerreiros capturados vieram de etnias que produziam arroz, como por exemplo, os Bamana (Bambara) e os Mandinga. A proporção masculina nos navios do tráfico de escravos que Eltis, Morgan e Richardson apresentam $^{18}$ não nos dizem nada sobre a possibilidade de os proprietários de plantações de arroz na Carolina, na Geórgia e no nordeste do Brasil preferirem mulheres de etnias que produziam arroz.

Um caso mais consistente - a propósito da preferência por mulheres que soubessem cultivar o arroz - pode ser observado a partir dos preços médios, por sexo, entre as etnias que cultivavam esse cereal. Na Luisiana, durante a década de 1770, o preço médio das mulheres das etnias produtoras de arroz, Mandinga e Jalofo, arroladas nas propriedades rurais, era mais alto do que o dos homens. Entre os Bamana (Bambara), outra etnia produtora de arroz, o preço médio das mulheres era ligeiramente inferior ao dos homens, durante a década de 1770 , e mais alto, no caso das mulheres, entre 1810 e 1820 . O preço médio das mulheres Jalofo era mais elevado do que o dos homens durante o período espanhol (17701803). As habilidades dessas mulheres na produção de arroz devem contar, pelo menos parcialmente, para esse padrão de preços atípico.

Tabela 2: Preço médio de homens e mulheres pertencentes a etnias produtoras de arroz arroladas em inventários de propriedades rurais na Luisiana, 1770-1820.

\begin{tabular}{|c|c|c|c|c|c|c|c|}
\hline Décadas & Etnias & $\begin{array}{c}\text { Número } \\
\text { de homens }\end{array}$ & Média & $\begin{array}{c}\text { Desvio } \\
\text { padrão }\end{array}$ & $\begin{array}{c}\text { Número de } \\
\text { mulheres }\end{array}$ & Média & $\begin{array}{c}\text { Desvio } \\
\text { padrão }\end{array}$ \\
\hline $1770-1779$ & Bamana & 7 & 282.66 & 26.904 & 3 & 266.67 & 61.101 \\
\hline & Mandinga & 18 & 297.78 & 87.753 & 5 & 312.00 & 45.497 \\
\hline & Jalofo & 9 & 235.56 & 107.251 & 5 & 288.00 & 56.619 \\
\hline $1770-1803$ & Jalofo & 96 & 321.87 & 236.861 & 188 & 331.23 & 260.229 \\
\hline $1810-1820$ & Bamana & 45 & 420.22 & 261.008 & 7 & 511.43 & 316.882 \\
\hline
\end{tabular}

Calculado a partir de HALL, Gwendolyn Midlo. Louisiana Slave Database, 1719-1820. Explicações sobre preços, fórmulas de conversão de preços e estudos de preços médios com base no sexo e na etnia, por década, para os africanos arrolados em inventários de propriedades rurais da Luisiana podem ser encontrados em HALL, Gwendolyn Midlo, Slavery and African Ethnicities in the Americas: Restoring the Links, Apêndice A, p. 173-179. 
Eltis, Morgan e Richardson alegam que cálculos efetuados a partir dos dados contidos no TSTD2 provam que os africanos da Alta Guiné não poderiam ter introduzido o arroz, ou os sistemas de cultivo e processamento, nas Américas, nem que os grandes proprietários voltados a essa produção os preferissem ou os escolhessem. ${ }^{19}$ Argumentam que poucos escravos da Alta Guiné chegaram a regiōes que se tornaram exportadoras de arroz, quando este começou a ser cultivado. Para períodos posteriores, eles descartam o impacto significativo nos padróes do tráfico escravo transatlântico da proporção relativamente alta de escravos africanos trazidos de regióes produtoras de arroz na África para regiōes exportadoras de arroz nas Américas, apontando para outros fatores, entre os quais não figuram as preferências dos compradores de escravos. ${ }^{20}$ Isto não é novidade. O livro desta autora, Slavery and African Ethnicies in the Americas: Restoring the Links, citado diversas vezes em "Agency and Diaspora...", em outros contextos, apresenta um capítulo inteiro dedicado a vários padrões desenvolvidos no tráfico escravo Atlântico como um todo, incluindo as forças do mercado. As preferências dos compradores de escravos por etnias particulares são tratadas como apenas mais um fator, entre outros. ${ }^{21}$

Não fica claro o que os cálculos citados por Eltis, Morgan e Richardson, a partir do TSTD2, podem provar sobre um possível impacto africano no cultivo e processamento de arroz nas Américas. Quantas pessoas foram necessárias para introduzir e desenvolver o arroz em ambientes diversos? Será que o arroz foi introduzido apenas uma vez, após a qual os proprietários das fazendas aprenderam tudo o que precisavam sobre seu cultivo, apesar da diversidade de ambientes e ecossistemas em que foi produzido, ao longo do tempo? Será que foi preciso haver uma maioria, ou uma minoria significativa, de escravos africanos oriundos da Alta Guiné na época em que o arroz começou a ser produzido, ou uma porcentagem maior de africanos dessa região, dentre todos os escravos que chegavam ao Caribe e à Costa Leste dos Estados Unidos, mesmo que o arroz raramente fosse exportado do Caribe, e que a Costa Leste fosse uma região marginal para o tráfico de escravos? ${ }^{22}$ Documentos da Luisiana mostram que a Companhia das Índias solicitou, apenas, alguns escravos que pudessem ensinar como cultivar arroz. ${ }^{23}$

Carney talvez subestime, e Eltis, Morgan e Richardson nem mencionam, o possível papel de Madagascar na introdução do arroz nas Américas. Imigrantes do Ceilão começaram a povoar Madagascar por volta de 800 d.C., trazendo com eles o arroz asiático [oryza sativa] e técnicas para seu cultivo e processamento. TSTD2 contém registros de dez navios que chegaram a Barbados, entre 1664 e 1683, e de dezessete, à Costa Leste dos Estados Unidos, entre 1686 e 1721, todos provenientes de Madagascar. Houve também, partindo de Madagascar, viagens do tráfico escravo realizadas por contrabandistas, corsários e piratas de diversas nacionalidades, que não foram registradas no banco de dados.

Além dos navios provenientes da Alta Guiné, registrados no TSTD2, qualquer um desses, ou de outros, dentre os 749 cuja procedência é registrada no banco de dados como "porto africano não especificado", poderia ter transportado grãos de arroz e uma quantidade suficiente de africanos que soubesse cultivá-lo, processá-lo e que pudesse ensinar essas habilidades aos seus senhores. Conclusões sobre o papel exercido, ou não, pelos africanos na introdução do arroz nas Américas não podem ser extraídas do TSTD2, cujos cálculos são baseados em regiões e não, em etnias africanas. O trabalho de campo cuidadoso, exaustivo, multilinguista e multidisciplinar de Carney, bem como seus estudos sobre documentos escritos em diversas línguas, cobrindo uma ampla extensão de tempo e espaço no mundo Atlântico, são muito mais convincentes. Além do mais, Edda L. Fields-Black, em seu livro Deep Roots: Rice Farmers in West Africa and the African Diaspora - que examina, principalmente, evidências sociolinguísticas juntamente com fontes históricas tradicionais -, estabelece a duração temporal e a variedade de cultivos de arroz, envolvendo heranças, inovações e empréstimos entre diversas etnias que habitavam a Costa do Arroz na Alta Guiné e sua transferência para as Américas ao longo do tempo. ${ }^{24}$ 


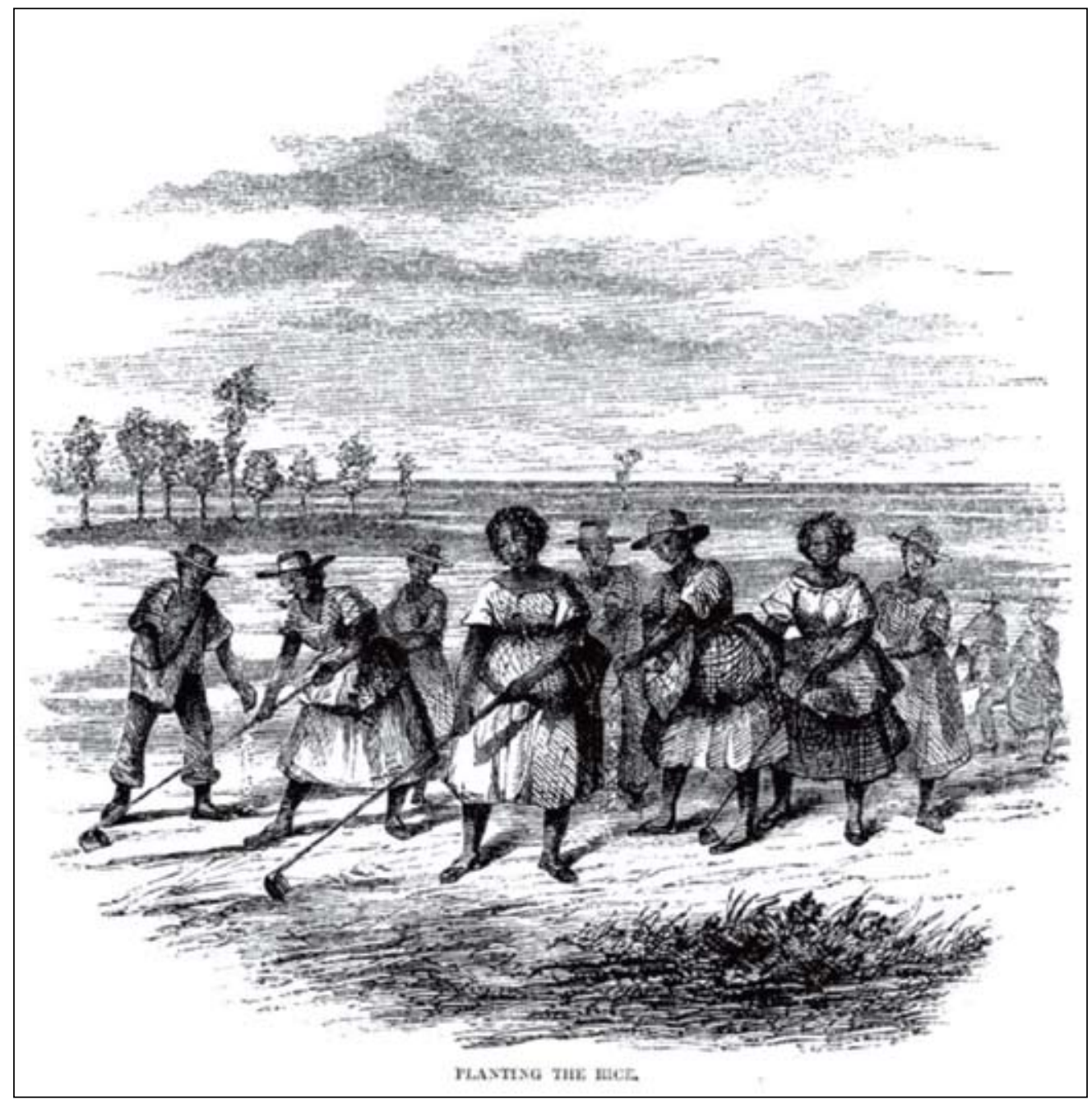

Figura 2: "Plantando Arroz", de T. Addison Richards.

Em "The Rice Lands of the South", Harper's New Monthly Magazine, Novembro 1859, 726.

Eltis, Morgan e Richardson misturam duas variáveis distintas: a produção de arroz e a exportação para a Europa. Essa definição estreita realça seus argumentos de que os proprietários controlavam totalmente as decisões relacionadas à produção, processamento e comercialização do arroz. A produção das comunidades maroon (escravos fugidos) é desconsiderada, como de pouca importância. O mercado doméstico do arroz é relegado a uma produção de subsistência, ou a um "sistema que gerou exportações, ao invés da exportação propriamente dita” ${ }^{25}$ Culturas alimentares foram introduzidas e permutadas em todo o mundo Atlântico. Os escravos trabalhavam suas próprias parcelas de terra, produziam e vendiam todo tipo de alimento, como arroz, milho, feijão, frutas, vegetais, ovos, aves, porcos, presunto e carne defumada. $\mathrm{Na}$ Carolina do Sul, na Jamaica e na Luisiana, os escravos eram os maiores fornecedores de alimentos para as cidades e povoados. Os europeus e os africanos - principalmente os da primeira geração -, assim como os índios americanos, preferiam consumir os cereais a que estavam acostumados. Na Luisiana, os europeus preferiam trigo, os índios, milho, e os africanos preferiam arroz. Mas, essas preferências nem sempre determinam os tipos de cereais que consumiam. Todos comiam qualquer coisa que conseguissem encontrar durante as guerras frequentes, quando não havia comida importada e os alimentos eram escondidos por especuladores, e também durante furacões e enchentes, quando a produção de arroz era maior do que qualquer outra safra. Até no caso das plantations da Carolina que produziam arroz e o exportavam para a Europa, os autores de "Agency and Diaspora..." exageram o poder e controle que os senhores tinham sobre os escravos. Os europeus não eram todo-poderosos, 
especialmente em termos de economia e de cultura. Também eles eram estranhos em uma terra estranha, perigosa e hostil. O controle não estava sempre firme em suas mãos, sobretudo durante as etapas iniciais e cruciais da formação da economia e da cultura. O estudo de William Dusinberre sobre a vida nas plantações de arroz da Carolina e da Geórgia revela que os proprietários e suas famílias frequentemente estavam ausentes daquele ambiente de febres mortais. Os proprietários não conseguiam capatazes brancos para trabalhar nos pântanos de arroz. Durante o século XIX, capatazes escravos negros foram os supervisores dos trabalhadores escravos. Mas, esses capatazes escravos que gozavam da confiança de seus senhores, foram, frequentemente, os líderes de conspirações e revoltas escravas. ${ }^{26}$

"Agency and Diaspora..." minimiza o interesse dos compradores nas habilidades dos africanos: "Os compradores de escravos nas Américas queriam um suprimento barato de mão-de-obra indiferenciada para o trabalho no campo; e os fornecedores procuravam lugares na África onde pudessem obter um grande número de escravos rapidamente e por um custo razoável". ${ }^{27}$ Louisiana Slave Database registra uma gama impressionante de expertise nos escravos nascidos na África. Milhares de africanos que chegaram à Luisiana vieram de regiōes reconhecidas por certas perícias. Embora possamos consultar esse banco de dados em busca do registro dessas habilidades nos escravos nascidos na África, ele não pode nos informar se eles as trouxeram com eles, embora saibamos que eram largamente praticadas em suas terras natais na África. Porém, o banco de dados é altamente sugestivo em relação à transferência dessa expertise pelos escravos africanos que chegaram às Américas.

Uma circunstância oportuna nos dá uma prova ainda mais forte da transferência da tecnologia e das habilidades africanas. Tendo reclamado por anos que não conseguiam encontrar ninguém que soubesse como produzir e processar índigo, as autoridades coloniais da Luisiana solicitaram às autoridades francesas coloniais o envio de alguém que possuísse tal conhecimento. Pouco depois da chegada de africanos da Senegâmbia, em 1721, a Luisiana começou a produzir índigo, de forma experimental; em pouco tempo, esse produto tornou-se o principal na pauta de exportações. Na Luisiana Francesa, os capitães dos dois primeiros navios de tráfico escravo que chegaram da costa africana, em 1719, foram oficialmente instruídos a "tentar comprar vários negros que soubessem como cultivar arroz e três ou quatro barris de arroz para plantio, a serem dados aos diretores da Companhia das Índias, quando chegassem à Luisiana”. O primeiro navio, l'Aurore, deteve-se em Cabo Lahou em 28 de agosto de 1718, onde essas instruções poderiam ter sido cumpridas, e então se dirigiu a Whydah para comprar escravos. A produção de arroz na Luisiana expandiu-se rapidamente depois disso, à medida que quase todos os navios do tráfico escravo transatlântico passaram a vir da Senegâmbia. Durante a administração francesa (16991769), o arroz era embarcado da Luisiana para o Caribe Francês e para a Pensacola Espanhola [na Flórida]. Era amplamente cultivado em solos pantanosos, que não necessitavam de irrigação, enquanto o índigo, o milho e outras safras eram cultivadas nas mesmas fazendas e propriedades rurais em terras altas próximas dos rios. Durante a administração espanhola (1770-1803), o arroz foi embarcado para o Caribe Francês e para Havana, enquanto a monocultura de açúcar em Cuba expandia-se. A Luisiana começou a atender as necessidades de Cuba por alimentos de todos os tipos, incluindo arroz. Teriam os brancos ensinado aos ignorantes africanos todas essas habilidades? Parece óbvio que as diversas populaçôes da Luisiana - africanos, creoles, cajuns, canadenses, franceses, alemães, espanhóis, canarinos [oriundos das Ilhas Canárias] e índios - ensinaram uns aos outros. ${ }^{28}$ 


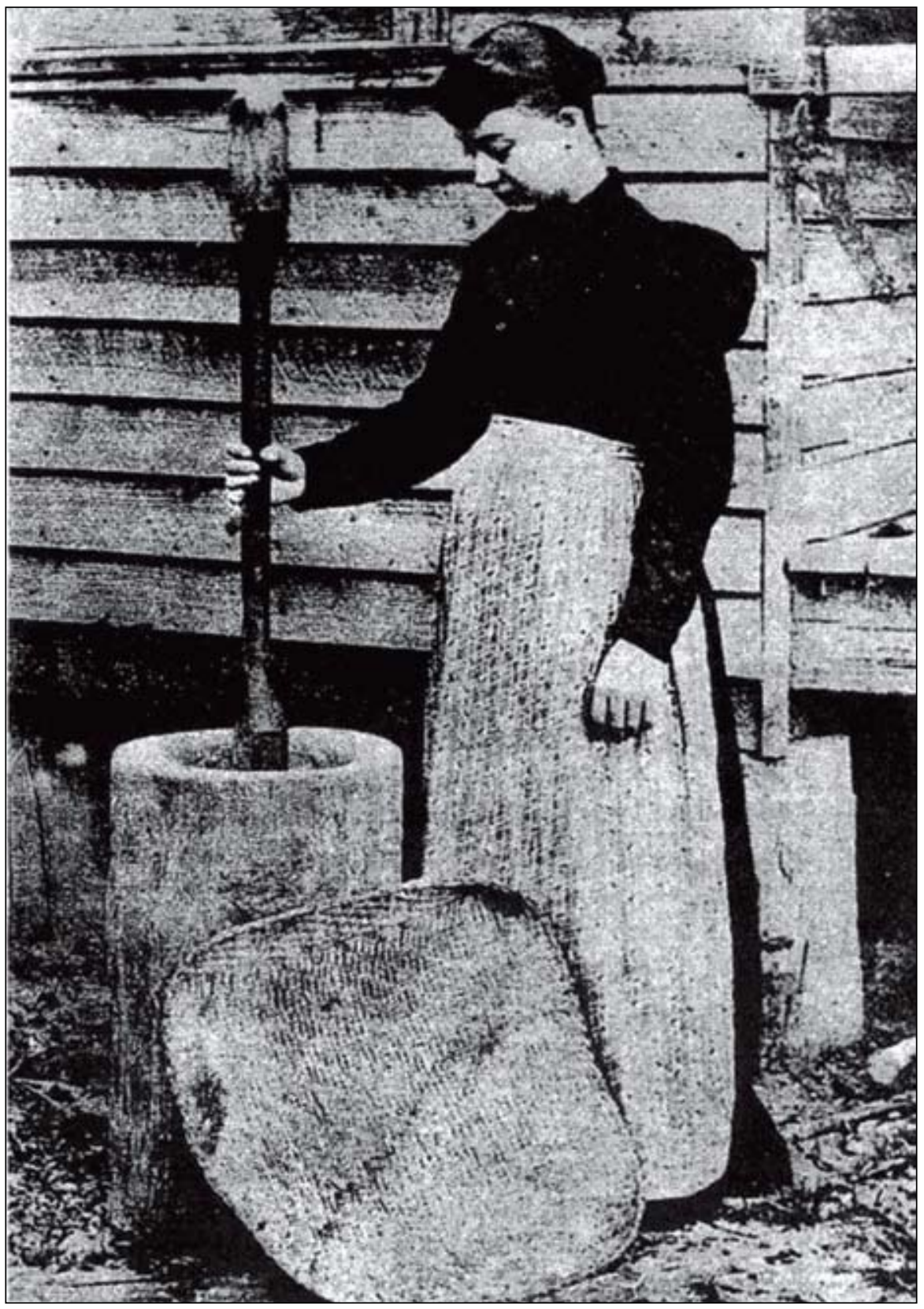

Figura 3: Jovem acadiana [proveniente da região oriental do Canadá] com pilão usado para descascar arroz. Rowley Signal, 20 de janeiro de 1904.

Eltis, Morgan e Richardson exageram de forma considerável aquilo que podemos depreender, a partir dos cálculos derivados do TSTD2, acerca da distribuição dos africanos nas Américas. Vimos que os africanos recém-chegados frequentemente eram vendidos e depois transferidos para seus destinos finais, fora da colônia onde haviam primeiro desembarcado. Documentos produzidos e conservados nas Américas mostram que, a cada estágio da sua redistribuição, os compradores podiam selecionar - e muitas vezes o fizeram - africanos de determinadas regióes e/ou etnias. Em Cuba, Manuel Barcia e Matt D. Childs encontraram agrupamentos de etnias africanas em plantations, em cabildos de naciones e entre escravos rebeldes. Em Santo Domingo, Haiti, Gabriel Debien e David Geggus encontraram agrupamentos de etnias africanas em propriedades rurais individuais. Na Luisiana Espanhola, nativos da Alta Guiné foram agrupados de forma desproporcional na paróquia de St. Charles, que produzia arroz, e na paróquia de St. Landry, onde havia criação de gado. Dentre os escravos nascidos na África, a paró- 
quia de St. Landry tinha uma proporção bem maior de oriundos da Alta Guiné, mais do que qualquer outra paróquia: 67,9\% (73\% homens) dos escravos com local de nascimento identificado. Na África Ocidental, não havia criação de gado nem pastoreio, na região leste da Alta Guiné, pela ocorrência da mosca tsé-tsé. A paróquia de St. Landry permanece como local tradicional dos vaqueiros afro-creole e da música $z y d e c o .{ }^{29}$ As viagens transatlânticas do tráfico de escravos, por si sós, não podem nos dizer muito mais do que Eltis, Morgan e Richardson afirmam sobre as proporções de homens e mulheres dentre as etnias africanas, ou sobre a distribuição dos africanos nos seus destinos finais nas Américas.

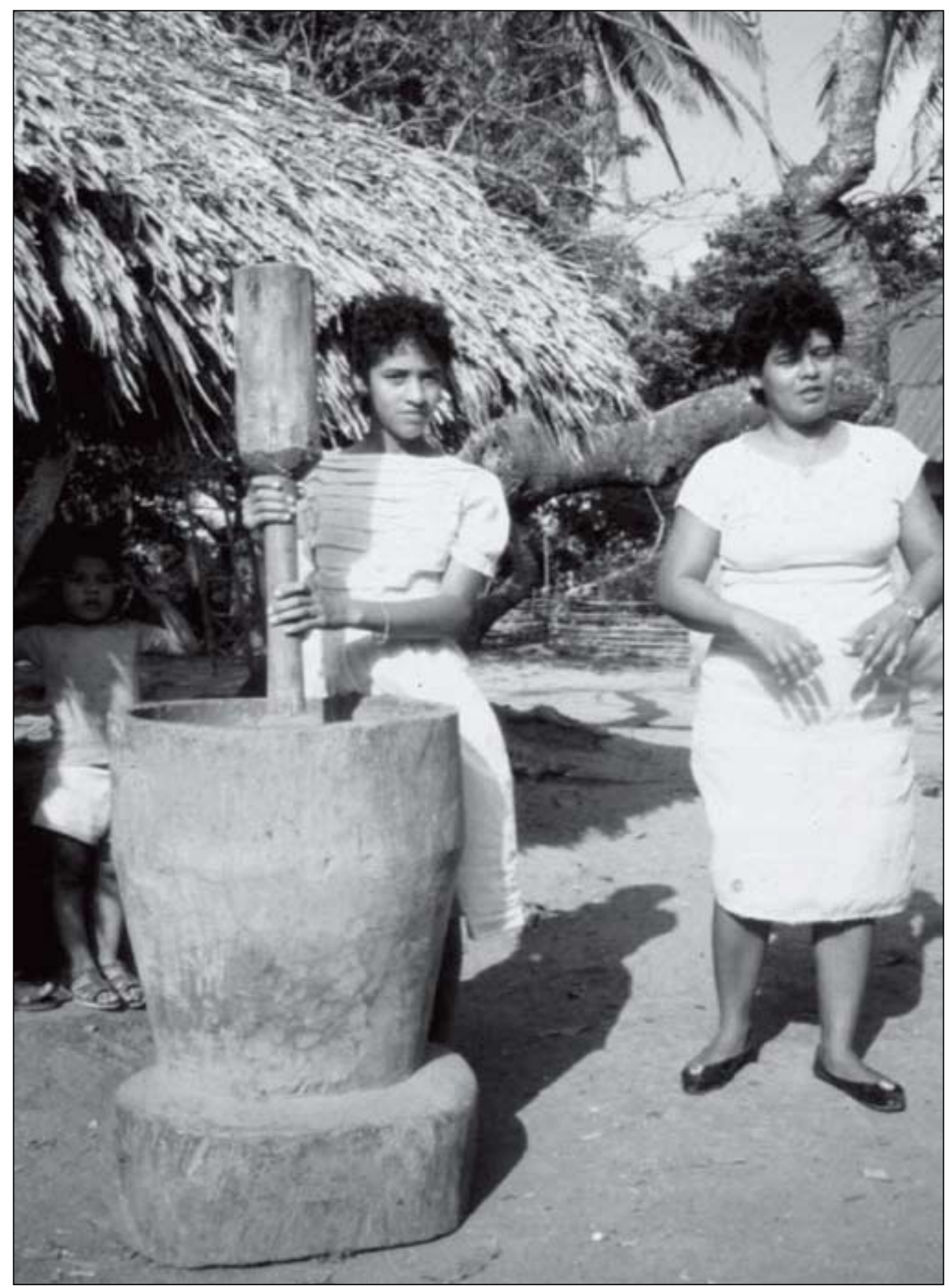

Figura 4: Mulheres moendo arroz em Mandinga, México, 1988. Fotografia de Judith A. Carney.

Os bancos de dados históricos são ferramentas novas e extraordinárias e mais pesquisadores deveriam aprender como usá-los e criá-los. Eles devem ser empregados em larga escala, mas de forma sensata 
e criteriosa, com uma compreensão das suas limitações. No entanto, dependendo de como são projetados e das perguntas para as quais são programados, eles podem ser rígidos e inflexíveis, prendendo-se a um questionário ultrapassado e não abrindo espaço a novas indagações. Os bancos de dados não são uma forma superior de conhecimento que possa, de alguma maneira, prevalecer sobre outros tipos de pesquisa. A sabedoria não é um jogo de soma-zero. ${ }^{30}$ Quando pesquisadores exageram nas questões a que um banco de dados consegue responder e criticam o trabalho de outros, por meio de cálculos irrelevantes, isto enfraquece seriamente nossa tarefa, difícil, mas essencial, de informar aos nossos colegas sobre o valor incomparável de bancos de dados históricos na realização de estudos abrangentes e comparativos. Precisamos valorizar o que outros fizeram e encorajar diversos pesquisadores a usar uma variedade de metodologias na elaboração do importante trabalho que fazem melhor. Apesar da grande complexidade dessas questões, a longa lista de pesquisadores seniores, assim como os da nova geração, criticados em "Agency and Diaspora...", estão constantemente realizando novas descobertas, cujo valor e impacto serão ampliados pelo rápido avanço da tecnologia.

Houve um significativo progresso na metodologia histórica desde a Segunda Guerra Mundial. Desenvolvemos a história social: a história "vista de baixo". Conceitos referentes aos valores positivos da mistura de raças e da "crioulização" foram introduzidos por meio dos trabalhos de José Vasconcelos, no México, Gilberto Freyre, no Brasil, e Edward (Kamau) Brathwaite, em Barbados. ${ }^{31}$ Nossa maior força é a nossa crescente aceitação da diversidade. Vivemos em um mundo que "encolhe" rapidamente, onde conflitos étnicos e religiosos são incitados e explorados por ambiciosas burocracias políticas, militares e religiosas e pelas elites econômicas. Não é tanto o fato de que as pessoas são intolerantes com "o outro", mas, sim, de que os sistemas sociais e seus ideólogos provocam e exploram esses conflitos. História é arte aplicada, ciência e literatura; ela pode ensinar apreço mútuo e respeito entre os povos. Os autores de "Agency and Diaspora..." deram um grande salto para trás nessa tarefa. À medida que o TSTD2 for revisado e melhorado, seus editores precisam torná-lo mais flexível, evitando, assim, que se chegue a resultados inválidos, a partir de evidências indiretas, incompletas e imperfeitas. Caso contrário, nosso trabalho será desacreditado por conclusões abusivas. Os cálculos efetuados a partir do TSTD2, que Eltis, Morgan e Richardson citam em seu artigo, podem ser impressionantes, mas esses historiadores não olham para o que não querem ver e não conseguem olhar para o que não têm. Suas conclusões passam longe de suas evidências.

Publicado originalmente em The American Historical Review, vol. 115, nº. 1, Fevereiro de 2010.

Tradução: Maria Carmelita P. Dias. Revisão técnica e edição: Maria Aparecida Rezende Mota.

\footnotetext{
Notas

${ }^{1}$ ELTIS, David; MORGAN, Philip; RICHARDSON, David. Agency and Diaspora in Atlantic History: Reassessing the African Contribution to Rice Cultivation in the Americas. American Historical Review, vol. 112, no . 5, p. 1329-1358, dezembro de 2007.

${ }^{2}$ MORGAN, Philip (ed.). Forum Albion's Seed: Four British Folkways in the Americas - A Symposium. The William and Mary Quarterly. 3 ${ }^{\text {rd. }}$ ser., vol. 48, no. 2, p. 224-308, 1991.

${ }^{3}$ ELTIS, David; MORGAN, Philip; RICHARDSON, David. Op. cit., p. 1332.

${ }^{4}$ HALL, Gwendolyn Midlo. Slavery and African Ethnicities in the Americas: Restoring the Links. Chapel Hill, N. C., 2005. p. 166-167; HEYWOOK, Linda M. \& THORNTON John K. Central Africans, Atlantic Creoles and the Foundation of the Americas, 1585-1660. Cambridge, 2007. Ver minha resenha do livro de Heywood e Thornton em Journal of Interdisciplinary History, vol. 39, nº. 3, p. 463-464, Inverno de 2009.
} 
${ }^{5}$ O TSTD2 calcula que 5.099.816 africanos escravizados foram desembarcados por navios portugueses e brasileiros e 2.733.323, por navios britânicos.

${ }^{6}$ INIKORI, Joseph E. "The Known, the Unknown, the Knowable and the Unknowable: Evidence and the Evaluation of Evidence in the Measurement of the Trans-Atlantic Slave Trade" (artigo inédito apresentado no Colóquio Trans-Atlantic Slave Trade Database, em Williamsburg, Virginia, em setembro de 1998); HALL, Gwendolyn Midlo. Slavery and African Ethnicities in the Americas: Restoring the Links. Op. cit., 2005. p. 68-79; CHAMBERS, Douglas B. Slave Trade Merchants of Spanish New Orleans, 1763-1803: Clarifying Slave Trade to Louisiana in Atlantic Perspective. Atlantic Studies, vol. 5, no. 3, p. 335-346, 2008.

${ }^{7}$ ELTIS, David; MORGAN, Philip; RICHARDSON, David. Op. cit., p. 1349.

${ }^{8}$ NGOU-MVE, Nicolás. Historia de la población negra en México: necessidad de un enfoque triangular. In: GUTIÉRREZ, Maria Elisa Velázquez e DURÓ, Ethel Correa (eds.). Poblaciones y culturas de origen africana en México. México, 2005. p. 39-64, p. 51; HALL, Gwendolyn Midlo. Africans in Colonial Louisiana: the Development of Afro-Creole Culture in the Eighteenth Century. Baton Rouge, La., 1992. p. 56-95.

${ }^{9}$ COHEN, Daniel J. Notas em Interchange: The Promise of Digital History. Journal of American History, vol. 95, no. 2, setembro 2008. p. 463.

${ }^{10} \mathrm{O}$ Louisiana Slave Database está disponível em <http://www.ibiblio.org/laslave>. A ferramenta de busca pode ser usada em vários campos e o banco de dados completo pode ser baixado gratuitamente em diversos formatos. Para uma discussão sobre a sua origem e as possibilidades de criação de outros bancos de dados, a partir de vários tipos de documentos manuscritos originais conservados nas Américas, ver <http://afropop.org/multi/ interview/ID/76/Gwendolyn_Midlo_Hall-2005>.

${ }^{11}$ ELTIS, David; MORGAN, Philip; RICHARDSON, David. Op. cit., p. 1347.

${ }^{12}$ Idem, ibidem, p. 1357.

${ }^{13}$ CARNEY, Judith A. Black Rice: The African Origins of Rice Cultivation in the Americas. Cambridge, Mass., 2001. p. xii, 66-67, 144-145, 154-157, 164-167.

${ }^{14}$ ELTIS, David; MORGAN, Philip; RICHARDSON, David. Op. cit., p. 1333.

${ }^{15}$ Idem, ibidem, p. 1347.

${ }^{16}$ Idem, ibidem, p. 1354.

${ }^{17}$ Idem, ibidem, p. 1348.

${ }^{18}$ Idem, ibidem, p. 1350-1351, Tabelas 5-7.

${ }^{19}$ Idem, ibidem, p. 1335-1338, Tabelas 1 e 2.

${ }^{20}$ Idem, ibidem, p. 1335, 1342, 1345.

${ }^{21}$ HALL, Gwendolyn Midlo. Slavery and African Ethnicities in the Americas: Restoring the Links. Op. cit., p. 55-79.

${ }^{22}$ ELTIS, David; MORGAN, Philip; RICHARDSON, David. Op. cit., p. 1337, 1338, Tabela 2.

23 "Instructions pour le sieur Herpin, commandant du vaisseu L'Aurore, destiné pour la traite des nègres à La coste de Guynée", 4 de Julho, 1718, Seção Marinha, Arquivos Nacionais, Paris, série B42B, fólios 201-204.

${ }^{24}$ FIELDS-BLACK, Edda L. Deep Roots: Rice Farmers in West Africa and the African Diaspora. Bloomington, Ind., 2008.

${ }^{25}$ ELTIS, David; MORGAN, Philip; RICHARDSON, David. Op. cit., p. 1343.

${ }^{26}$ HALL, Gwendolyn Midlo. Africans in Colonial Louisiana: the Development of Afro-Creole Culture in the Eighteenth Century. Op. cit., p. 21, 24, 123-124, 343-375; DUSINBERRE, William. Them Dark Days: Slavery in the American Rice Swamps. Nova York, 1996; PAQUETTE, Robert L. The Drivers Shall Lead Them: Image and Reality in Slave Resistance. In: PAQUETTE, Robert L. \& FERLEGER, Louis A. (eds.). Slavery, Secession and Southern History. Charlottesville, Va., 2000. p. 31-58.

${ }^{27}$ ELTIS, David; MORGAN, Philip; RICHARDSON, David. Op. cit., p. 1339.

${ }^{28}$ Entre os que detêm tais habilidades estão vaqueiros, criadores de gado e cavalos, treinadores de cavalos e cavalariços, trabalhadores de couro, curtidores, seleiros, sapateiros, açougueiros, cozinheiros, padeiros, confeiteiros, doceiros, fabricantes de chocolate, fabricantes de rum, fabricantes de charutos e de derivados do tabaco, ourives, artesãos de prata, ceramistas, fabricantes de índigo, alfaiates, chapeleiros, fabricantes de carvão, cesteiros, fabricantes de fornos, barbeiros, fabricantes de perucas, fiandeiros, condutores de carruagens e carroças, administradores de plantations, capatazes, feitores, pedreiros, pintores, estucadores, construtores de chaminés, artesãos de litografia, moleiros, ferreiros, fabricantes de ferramentas, afiadores, trabalhadores de metal, fabricantes de fogos de artifício, fabricantes de rodas de carroças, lenhadores, caçadores, pescadores, madeireiros, carregadores de madeira, serralheiros, carpinteiros, marceneiros, chaveiros, oleiros, marinheiros, navegadores, sondadores, construtores de navios, fabricantes de velas de barco e de remos, calafates, tanoeiros, estalajadeiros, vendedores de rua, mordomos, criados, empregados domésticos, costureiras, lavadeiras, trabalhadores de hospitais, enfermeiros, parteiras, médicos, dentistas, cirurgiões, músicos e intérpretes de línguas. Ocupações definidas a partir dos campos referentes a habilidades do Louisiana Slave Database. 
${ }^{29}$ A palavra zydeco refere-se à música originada da combinação da tradição musical cajun com elementos do blues. Trata-se de um tipo de música que predomina entre a população negra da Luisiana de língua francesa. Nota do editor.

${ }^{30} \mathrm{Na}$ teoria dos jogos e na teoria econômica, soma-zero descreve uma situação em que o ganho de um participante, ou perda, é exatamente equilibrado pela perda ou ganho de outro participante(s). Se os ganhos totais dos participantes são somados, e as perdas totais são subtraídas, eles somam zero. Nota do editor.

${ }^{31}$ VASCONCELOS, José. The Cosmic Race: A Bilingual Edition. Traduzido e anotado por Didier T. Jaén. Baltimore, 1997 (Edição em espanhol, 1920); FREYRE, Gilberto. The Masters and the Slaves (Casa-Grande \& Senzala): A Study in the Development of Brazilian Civilization. Trad. Samuel Putnam. New York, 1946 (Edição em português, 1935); BRATHWAITE, Edward Kamau. The Development of Creole Society in Jamaica, 1770-1820. Oxford, 1971. 